\title{
Falling Through the Cracks: The Need to Include Acute Pancreatitis in Risk Assessment Models for Acute Deep Venous Thrombosis
}

\author{
James Kamau $^{1}$, Elisabeth Paul ${ }^{1}$, Mathai Chalunkal ${ }^{1}$, Richard Snyder ${ }^{2}$, Douglas S. Corwin ${ }^{3}$ \\ 1. Internal Medicine, St. Luke's University Health Network, Easton, USA 2. Internal Medicine, St. Luke’s University \\ Health Network, Easton, USA 3. Pulmonary and Critical Care, St. Luke's University Health Network, Easton, USA
}

Corresponding author: James Kamau, jamesk58@gmail.com

\begin{abstract}
Acute pancreatitis is an inflammatory condition caused by an insult to the pancreas. Pancreatitis is associated with local and systemic complications such as splenic vein thrombosis and systemic inflammatory response syndromes (SIRS), respectively. Pancreatitis increases the risk of deep vein thrombosis (DVT) through a combination of increased production of pro-inflammatory cytokines and systemic vascular injury. However, DVT and pulmonary embolism remain under-recognized and underappreciated complications of acute pancreatitis as they fall through the cracks in the commonly used venous thromboembolism (VTE) risk assessment model. We therefore propose that VTE prophylaxis needs to be considered by all clinicians when admitting and evaluating patients with acute pancreatitis and that acute pancreatitis needs to be included on the various VTE risk assessment calculators as it is a significant risk factor for the development of VTE.
\end{abstract}

Review began $11 / 02 / 2020$ Review ended 11/24/2020 Published 12/13/2020

\section{(c) Copyright 2020}

Kamau et al. This is an open access article distributed under the terms of the Creative Commons Attribution License CC-BY 4.0., which permits unrestricted use, distribution, and reproduction in any medium, provided the original author and source are credited.
Categories: Internal Medicine, Preventive Medicine, Hematology

Keywords: pancreatitis, dvt, vte, risk assessment

\section{Introduction}

Acute pancreatitis is an inflammatory condition caused by an insult to the pancreas. The most common etiologies include alcohol consumption and gallstones [1]. Pancreatitis is associated with local and systemic complications. An example of a localized complication is splenic vein thrombosis [2]; however, this is felt to be due to the close proximity of the pancreas and splenic vein, placing this particular vein at risk for damage secondary to leakage of inflammatory or proteolytic molecules. A systemic complication of acute pancreatitis is systemic inflammatory response syndrome (SIRS). This pancreatitis-induced SIRS is severe enough to cause systemic vascular injury [3]. It is this combination of endothelial damage, possible increased blood viscosity from dehydration (part of Virchow's triad), and increased production of proinflammatory cytokines that can result in the development of venous thrombosis elsewhere in the body. Other pro-inflammatory gastrointestinal conditions such as ulcerative colitis and Crohn's disease are associated with an increased risk of developing a venous thrombosis [4].

Deep vein thrombosis (DVT) and pulmonary embolism (PE) are under-recognized and underappreciated complications of acute pancreatitis. For hospitalized patients, risk assessment models for DVT, such as the Caprini Risk Score for assessing risk of DVT, are frequently used to determine individual patient requirements for prophylactic measures [5]. These venous thrombo-embolism (VTE) risk assessment models (RAM) play an important role in reducing the risk of VTE development in hospitalized patients [6]. Acute pancreatitis, however, does not feature in the risk criteria.

We report a patient with acute pancreatitis who subsequently developed deep venous thrombosis thought to be due to the combination of endothelial damage and increased inflammatory response of acute pancreatitis. We believe that, given the pro-thrombotic state induced by acute pancreatitis, and the substantial morbidity and mortality associated with VTE, this condition should be incorporated into the various risk assessment models for acute deep venous thrombosis.

\section{Case Presentation}

A 57-year-old female with a past medical history of depression and hypertension presented to the hospital with the chief complaint of intractable nausea and vomiting for three days prior to presentation in addition to chest pain that began a day prior to presentation. The chest pain was sharp, sub-sternal with radiation to the back and epigastrium. It was rated by the patient as being 10/10 in intensity.

Vital signs on admission included a temperature of 97.8 degrees Fahrenheit, heart rate 79 beats $/ \mathrm{min}$, blood pressure $170 / 77 \mathrm{mmHg}$, and respiratory rate of $16 / \mathrm{min}$ with an oxygen saturation of $99 \%$ on room air. On physical exam, at the time of admission, the patient was in mild distress with epigastric tenderness noted on palpation. The remainder of the physical exam was unremarkable. 


\section{Cureus}

Laboratory values included an elevated troponin level that peaked at $0.07 \mathrm{ng} / \mathrm{ml}$. Electrocardiogram showed normal sinus rhythm with sinus arrhythmia and non-specific ST and T wave changes. Aspartate

aminotransferase (AST) and alanine aminotransferase (ALT) levels were elevated at $337 \mathrm{U} / \mathrm{L}$ and $215 \mathrm{U} / \mathrm{L}$, respectively. Total bilirubin was normal at $0.38 \mathrm{mg} / \mathrm{dL}$. Lipase was noted to be elevated at $1,174 \mathrm{U} / \mathrm{L}$ with triglycerides at $124 \mathrm{mg} / \mathrm{dL}$. A right upper quadrant ultrasound showed cholelithiasis without evidence of choledocholithiasis or cholecystitis (Figure 1). Computed tomography (CT) scan of the abdomen and pelvis with contrast demonstrated fatty infiltration within the pancreaticoduodenal groove consistent with acute interstitial pancreatitis (Figure 2).

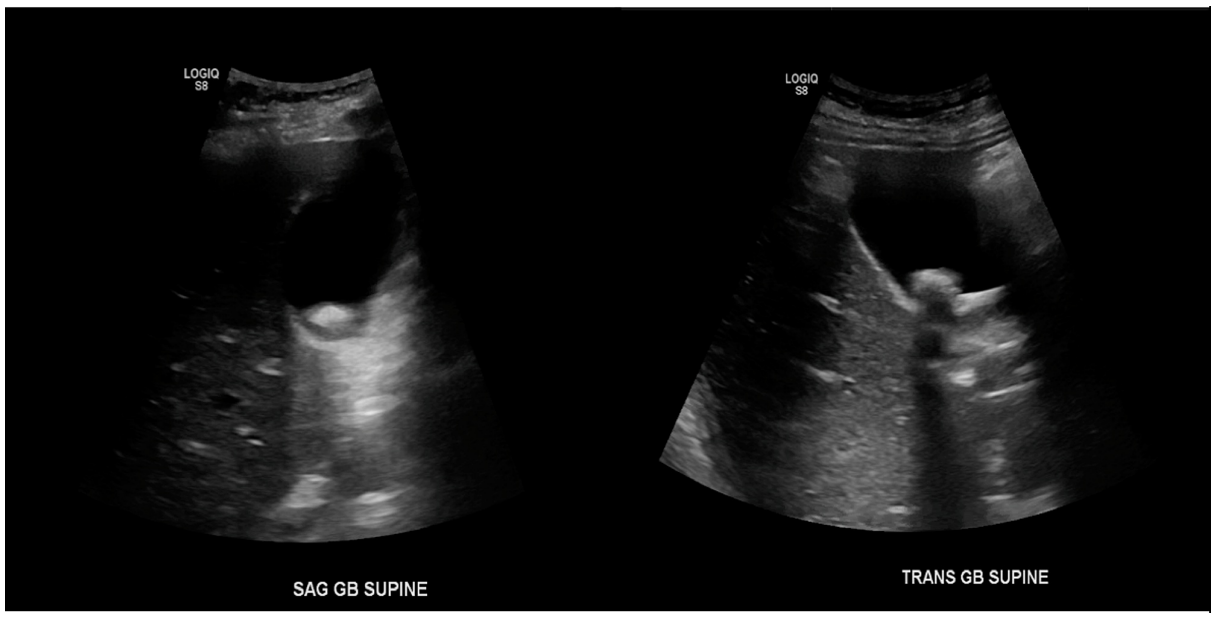

FIGURE 1: US of the abdomen demonstrating the gall bladder with no wall thickening or pericholecystic fluid. Shadowing gallstone(s) identified.

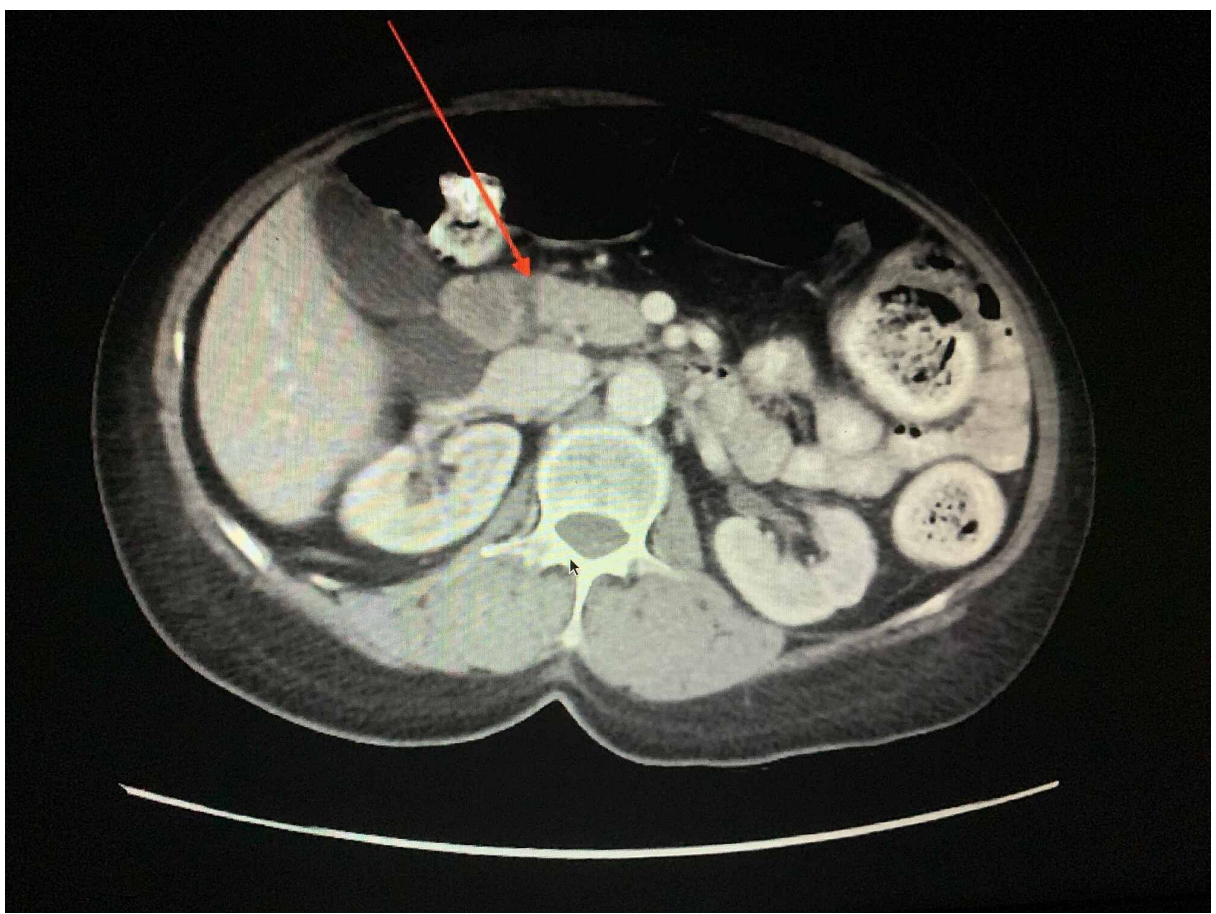

FIGURE 2: CT of the abdomen and pelvis demonstrating fat infiltration within the pancreaticoduodenal groove consistent with acute interstitial pancreatitis

The patient improved with intravenous volume resuscitation and electrolyte replacement. Her laboratory parameters improved to lipase $503 \mathrm{U} / \mathrm{L}$ (the next day), AST $11 \mathrm{U} / \mathrm{L}$, and ALT $52 \mathrm{U} / \mathrm{L}$ (over the course of five days). The patient was discharged after a five-day hospital stay. Further plan of care included outpatient 


\section{Cureus}

follow-up with her primary care provider, and surgical follow-up for consideration of elective cholecystectomy. During this admission, the patient was encouraged to ambulate but was not started on chemical VTE prophylaxis due to a low score (1 for age) based on a modified version of the Caprini VTE risk assessment calculator utilized at our institution (Figure 3).

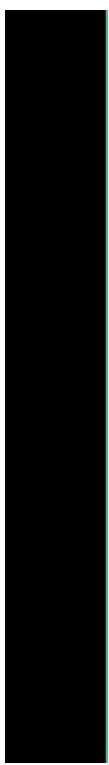

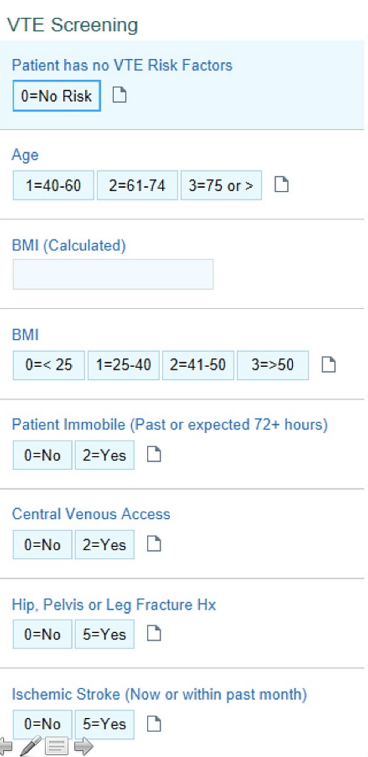

\begin{tabular}{|c|c|c|c|c|c|}
\hline \multicolumn{3}{|c|}{ Acute Spinal Cord Injury } & \multicolumn{2}{|c|}{ Malignancy } & \multirow[b]{2}{*}{$\square$} \\
\hline $0=$ No & $5=$ Yes & $\square$ & $0=$ No & $2=Y e s$ & \\
\hline \multicolumn{2}{|c|}{ Artrhroplasty } & \multirow[b]{2}{*}{$\square$} & \multicolumn{2}{|c|}{ Varicose Veins } & \\
\hline $0=$ No & $5=$ Yes & & $0=$ No & $1=$ Yes & 口 \\
\hline \multicolumn{3}{|c|}{ Known Thrombophilia } & \multicolumn{3}{|c|}{ Inflammatory Bowel Disease } \\
\hline $0=$ No & $3=Y e s$ & 口 & $0=$ No & $1=$ Yes & 口 \\
\hline \multicolumn{2}{|c|}{ DVT/PE HX } & & \multicolumn{2}{|c|}{ CHF or MI } & \\
\hline $0=$ No & $3=Y e s$ & $\square$ & $0=$ No & $1=Y e s$ & $\square$ \\
\hline \multicolumn{3}{|c|}{ Family History of DVT/PE } & \multicolumn{2}{|c|}{ Acute Infection } & \\
\hline $0=$ No & $3=$ Yes & ए & $0=$ No & $1=$ Yes & $\square$ \\
\hline \multicolumn{2}{|l|}{ COPD } & & \multicolumn{2}{|l|}{ Sepsis } & \\
\hline $0=$ No & $1=Y e s$ & $\square$ & $0=$ No & $1=$ Yes & $\square$ \\
\hline \multicolumn{3}{|c|}{ Acute Respiratory Failure } & \multicolumn{3}{|c|}{ Minor Surgery (Now or within past month) } \\
\hline $0=$ No & $2=Y e s$ & $\square$ & $0=$ No & $1=$ Yes & $\square$ \\
\hline \multicolumn{6}{|c|}{ Major Surgery (Now or within past Nephrotic Syndrome } \\
\hline $0=$ No & $2=Y e s$ & ए & $0=$ No & $1=$ Yes & $\square$ \\
\hline
\end{tabular}

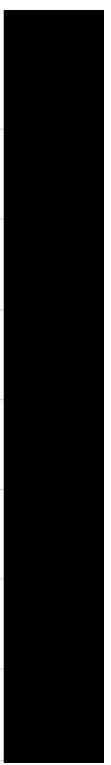

FIGURE 3: Venous thrombo-embolism (VTE) risk assessment calculator (Chemical prophylaxis indicated for score $>2$ ).

She returned to the hospital three days after discharge following a visit to her primary care physician who noted a significant difference in her calf circumference with the right leg larger than the left. There was an associated Moses' sign. Doppler ultrasound demonstrated acute occlusive deep vein thrombosis from the mid to distal femoral vein, popliteal vein and one of the posterior tibial veins in the proximal calf (Figure 4). The patient was subsequently readmitted and started on heparin infusion. While the CT angiogram showed a few small non-occlusive chronic emboli bilaterally, there was no evidence of an acute pulmonary embolus (Figure 5).

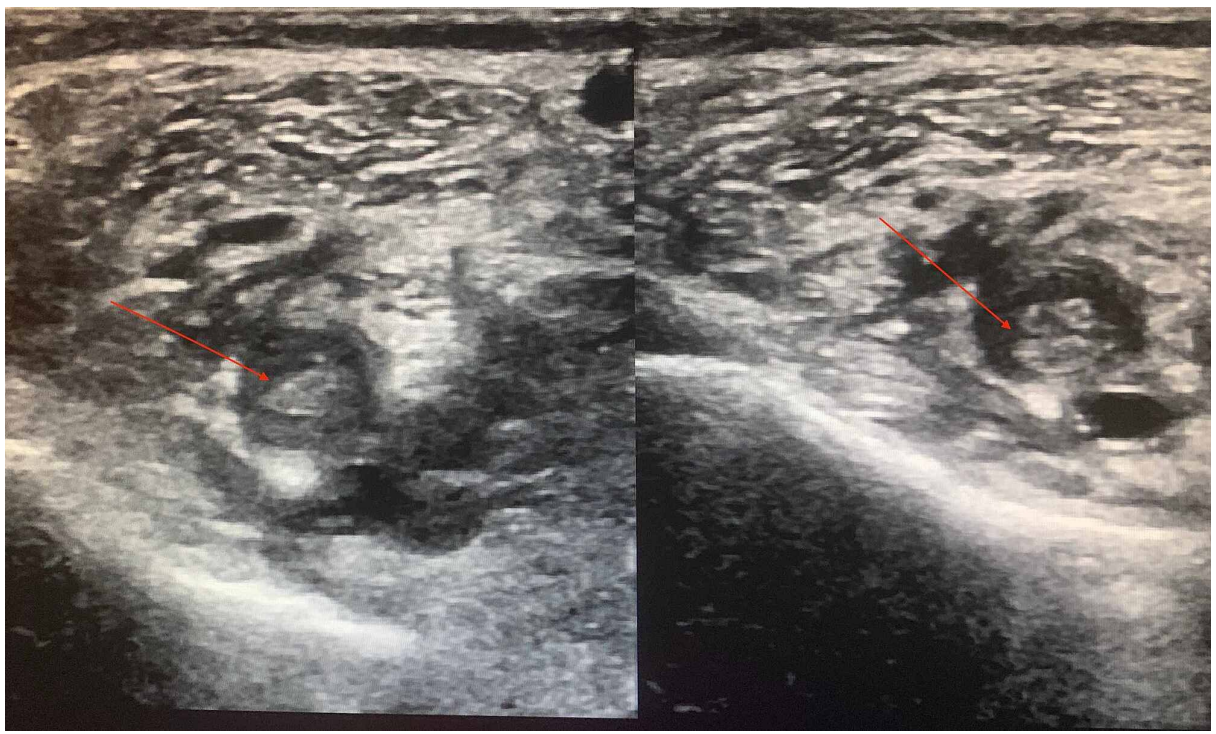

FIGURE 4: Lower Limb Venous Duplex showing deep vein thrombosis (DVT) in the popliteal vein 


\section{Cureus}

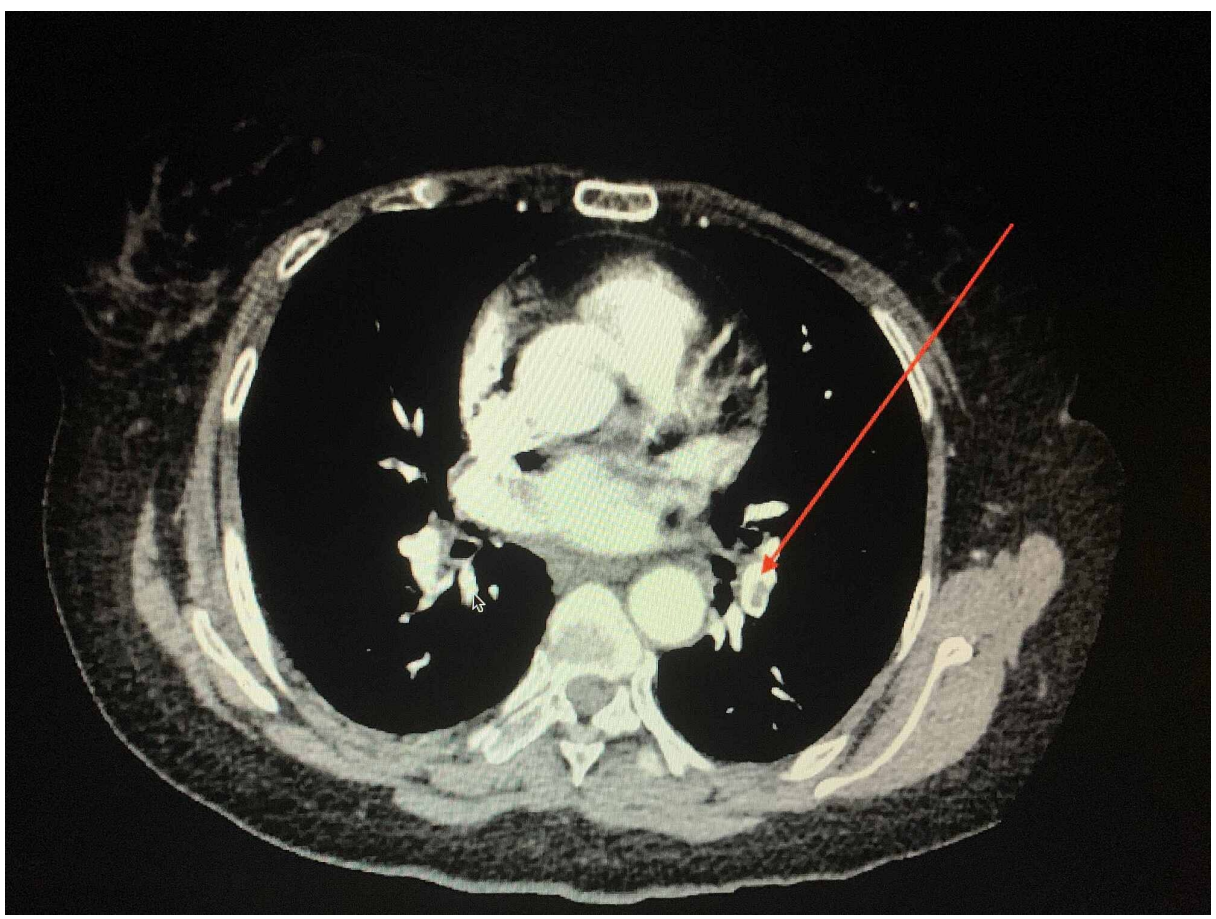

FIGURE 5: CT angiogram chest pulmonary embolism (PE) study demonstrating a small linear filling defect

\section{Discussion}

Validated VTE risk assessment models (RAM) such as Padua, Caprini and Geneva prediction scores [7] include co-morbidities shown to increase the risk for VTE formation such as active cancer, prior thrombotic episode, heart or respiratory conditions, infections and/or rheumatologic conditions. These RAM are effective in discriminating between medical patients at high and low risk for VTE [8]. High-risk patients should receive chemical prophylaxis, which substantially reduce their risk of developing a VTE [9]. Barbar et al. [6] using the Padua RAM, for example, showed that chemical VTE prophylaxis provided an $87 \%$ VTE risk reduction in high-risk patients who received VTE chemical prophylaxis compared to those that did not.

Acute pancreatitis, however, falls through the cracks in these RAM as it is neither an infection, rheumatologic condition, nor is it an active malignancy. Acute pancreatitis is an inflammatory reaction. It occurs following pancreatic cell damage that results in activation and induction of pro-inflammatory cytokines, notably IL-6, IL-8, and macrophage migration inhibitory factor [10], which in turn promote further parenchymal cell damage. Inflammation is intricately involved in venous thrombus formation and inflammation is postulated to be a "stimulus" or "catalyst" for the development of a pro-thrombotic state [11]. Fox et al. systemic review of clinical studies looking at the relationship between inflammation and thrombus, and found the same inflammatory markers (IL-6 and IL-8) to be involved in the pathogenesis of VTE [12]. Umapathy et al., on the other hand, looked at 2,453,997 discharges with acute pancreatitis and found that 23,614 (1\%) were associated with VTE [13-14]. The incidence of DVT and PE was almost two-fold higher in patients with acute pancreatitis than the controls irrespective of the sex, age, or comorbidity.

\section{Conclusions}

Venous thromboembolism remains an important but under-recognized complication of acute pancreatitis. Given that 10 to $30 \%$ of people will die within one month of diagnosis of VTE and one-third to one-half will have long-term complications, preventing such events should be considered "high stakes" and the threshold for implementing preventing measures low. We therefore propose that VTE prophylaxis needs to be considered by all clinicians when admitting and evaluating patients with acute pancreatitis and that acute pancreatitis needs to be included on the various VTE risk assessment calculators as it is a significant risk factor for the development of VTE.

\section{Additional Information}

\section{Disclosures}

Human subjects: Consent was obtained by all participants in this study. Conflicts of interest: In compliance with the ICMJE uniform disclosure form, all authors declare the following: Payment/services info: All authors have declared that no financial support was received from any organization for the 
submitted work. Financial relationships: All authors have declared that they have no financial relationships at present or within the previous three years with any organizations that might have an interest in the submitted work. Other relationships: All authors have declared that there are no other relationships or activities that could appear to have influenced the submitted work.

\section{References}

1. Wang GJ, Gao CF, Wei D, Wang C, Ding SQ: Acute pancreatitis: etiology and common pathogenesis . World J Gastroenterol. 2009, 15:1427-1430. 10.3748/wig.15.1427

2. Butler JR, Eckert GJ, Zyromski NJ, Leonardi MJ, Lillemoe KD, Howard TJ: Natural history of pancreatitisinduced splenic vein thrombosis: a systematic review and meta-analysis of its incidence and rate of gastrointestinal bleeding. HPB (Oxford). 2011, 13:839-845. 10.1111/j.1477-2574.2011.00375.x

3. Dumnicka P, Maduzia D, Ceranowicz P, Olszanecki R, Drożdż R, Kuśnierz-Cabala B: The interplay between inflammation, coagulation and endothelial injury in the early phase of acute pancreatitis: clinical implications. Int J Mol Sci. 2017, 18:354. 10.3390/ijms18020354

4. Andrade AR, Barros LL, Azevedo MFC, Carlos AS, Damião AC, Sipahi AM, Leite AA: Risk of thrombosis and mortality in inflammatory bowel disease. Clin Transl Gastroenterol. 2018, 9:142. 10.1038/s41424-018-0013 8

5. Caprini Score for DVT Risk. https://www.mdapp.co/caprini-score-for-dvt-risk-calculator-405/.

6. Barbar S, Noventa F, Rossetto V, et al.: A risk assessment model for the identification of hospitalized medical patients at risk for venous thromboembolism: the Padua Prediction Score. J Thromb Haemost. 2010, 8:2450-2457. 10.1111/j.1538-7836.2010.04044.x

7. Padua Prediction Score for Risk of VTE . https://www.mdcalc.com/padua-prediction-score-risk-vte.

8. Bahl V, Hu HM, Henke PK, Wakefield TW, Campbell DA Jr, Caprini JA: A validation study of a retrospective venous thromboembolism risk scoring method. Ann Surg. 2010, 251:344-350. 10.1097/SLA.0b013e3181b7fca6

9. Själander A, Jansson JH, Bergqvist D, Eriksson H, Carlberg B, Svensson P: Efficacy and safety of anticoagulant prophylaxis to prevent venous thromboembolism in acutely ill medical inpatients: a metaanalysis. J Intern Med. 2008, 263:52-60. 10.1111/j.1365-2796.2007.01878.x

10. Kay PS, Smith M, Brand M: The initiating immune response of acute pancreatitis may be mediated by the THelper 17 pathway. J Pancreas. 2017, 18:33-37.

11. Branchford BR, Carpenter SL: The role of inflammation in venous thromboembolism. Front Pediatr. 2018, 6:142. 10.3389/fped.2018.00142

12. Fox EA, Kahn SR: The relationship between inflammation and venous thrombosis. A systematic review of clinical studies. Thromb Haemost. 2005, 94:362-365. 10.1160/TH05-04-0266

13. Umapathy C, Gajendran Mahesh, Munigala S, Trikudanathan G: Prevalence of deep vein thrombosis (DVT) and pulmonary embolism (PE) in hospitalized acute pancreatitis (AP) patients - a population based cohort study. Am J Gastroenterol. 2016, 111:12.

14. Chung WS, Lin CL: Association between venous thromboembolism and acute pancreatitis: an analysis from the nationwide inpatient sample. Clin Respir J. 2020, 14:320-327. 10.1111/crj.13134 